\title{
Musical Similarity as Conceived by “Avid Recreational Music Listeners"
}

\author{
By Jason Neal \\ Recipient of the 2015 CAML First-Time Conference Presenter Award
}

\section{Abstract}

Over the past century, sociocultural and technological developments have fostered the emergence of what Peterson and Kern (1996) call "omnivorous" music listeners, who listen to music from a variety of different genres. As well, non-hierarchical forms of categorization, such as tagging, have appeared in recent years. Despite such trends, genre remains the primary basis for categorizing music in systems with content, metadata, or both. Furthermore, techniques employed within many recommender systems, intended to aid listeners with finding music for recreational listening, indirectly continue to reflect genre-based categorization and taste. This paper provides an overview of the contexts in which such trends have emerged. It also considers prospects for incorporating actively nuanced dimensions of similarity into recommender systems, which could enable users to engage in cross-genre music discovery more easily than current systems allow. To provide further grounding for such possibilities, I am currently conducting a study to determine how "avid recreational music listeners" conceptualize musical similarity. This paper discusses the study's methodology, which consists of semi-structured interviews and music-seeking exercises.

\section{Introduction}

Beginning in the twentieth century, various sociocultural factors and electronic forms of mass media have helped foster the emergence of what Peterson and Kern refer to as "omnivorous" musical tastes. ${ }^{1}$ Within this context, listeners could potentially find and enjoy music from

Jason Neal is currently a fifth-year PhD candidate at Western University (London, Ontario). Based on his doctoral research, this paper was presented at CAML's 2015 conference, which Neal attended as the recipient of the CAML First-Time Conference Presenter Award.

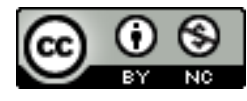

This work is licensed under a Creative Commons Attribution-NonCommercial 4.0 International License.

1. Richard A. Peterson and Roger M. Kern, "Changing Highbrow Taste: From Snob to Omnivore," American Sociological Review 61, no. 5 (1996): 900-907. 
diverse genres associated with high-, middle-, and lowbrow social statuses. ${ }^{2}$ Furthermore, as noted by such authors as Cope, ${ }^{3}$ Long, ${ }^{4}$ Ross, ${ }^{5}$ Schleifer, ${ }^{6}$ and Sullivan, ${ }^{7}$ musicians have created works that combine conventions associated with different genres, whether they derive from the same social status level or, as suggested by musical omnivorousness, different social status levels.

As Peterson and Kern observed in 1996, "the increasingly ubiquitous mass media have introduced the aesthetic tastes of different segments of the population to each other." ${ }^{8}$ In the two decades that have followed, such trends have continued due to the ubiquity of the Internet, wherein platforms with music-related metadata, audio content, or both, provide users with increasingly easier access to a diverse range of music. Examples include Amazon, iTunes,

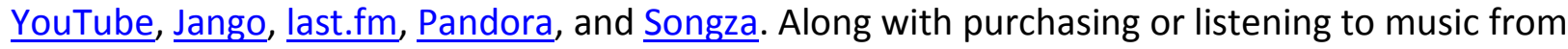
a variety of genres, users can also share comments and reviews.

Although reviews and comments can recommend further listening, a number of sites also draw upon collaborative filtering algorithms to "push" recommendations to users. "Item-to-item" algorithms draw upon users' previous interactions with specific content or item records, providing the foundation for suggestions of other seemingly similar items. "User-to-user" algorithms draw upon aggregated information about the on-site practices of users who share seemingly similar tastes, based on what they view, listen to, or purchase. Such algorithmic assessments of user- or item-based similarities can help users explore a specific genre. On the other hand, these techniques rely on systems-based data, which decontextualize user behaviours. Consequently, as pointed out by Bonhard and Sasse, ${ }^{9}$ Celma, ${ }^{10}$ and Celma and

2. Richard A. Peterson and Albert Simkus, "How Musical Taste Groups Mark Occupational Status Groups," in Cultivating Differences: Symbolic Boundaries and the Making of Inequality, ed. Michèle Lamont and Marcel Fournier (Chicago: University of Chicago Press, 1992), 152-168.

3. Andrew Cope, Black Sabbath and the Rise of Heavy Metal Music (Burlington, VT: Ashgate, 2010).

4. Michael Long, Beautiful Monsters: Imagining the Classic in Musical Media (Berkeley: University of California Press, 2008).

5. Alex Ross, The Rest Is Noise: Listening to the Twentieth Century (New York: Farrar, Straus and Giroux, 2007).

6. Ronald Schleifer, Modernism and Popular Music (New York: Cambridge University Press, 2011).

7. Jack Sullivan, New World Symphonies: How American Culture Changed European Music (New Haven: Yale University Press, 1999).

8. Peterson and Kern, "Changing Highbrow Taste," 905.

9. Philip Bonhard and Martina Angela Sasse, "Knowing Me, Knowing You: Using Profiles and Social Networking to Improve Recommender Systems," BT Technology Journal 24, no. 3 (2006): 84-98.

10. Òscar Celma, Music Recommendation and Discovery (Berlin, Heidelberg: Springer-Verlag Berlin Heidelberg, 2010). 
Lamere, ${ }^{11}$ users' perceptions of a recommender system's quality and usefulness can decline over time if the system does not yield new music that piques their interest, or if it does not sustain an appropriate balance of familiarity and novelty. Furthermore, recommender systems cannot account for potential changes in users' musical preferences over time. As well, these systems tend to favour popular items due to higher usage. Conversely, less popular genres and "niche" items, along with many new works, have little or no data regarding usage, which decreases their likelihood of being recommended. ${ }^{12}$ With these kinds of limitations, users may struggle to find a broad range of music they might perceive as "similar" to what they already like, whether it comes from unfamiliar genres or across a range of genres.

The problematic aspects of recommender systems relate closely to genre's ongoing importance as a marker of taste and mode of music categorization. This article discusses how genre has emerged as the primary mode of categorizing music and indicating musical similarity. It also considers possibilities for alternative modes of similarity that can broaden prospects for music discovery. Finally, it outlines the parameters of my doctoral research, which specifically focuses on the ways self-described "avid recreational music listeners" conceptualize musical similarity. The findings of this study, which is currently in the final stages of data collection, may have implications for how we could actively broaden the notion of "similarity" and expand the possibilities of music discovery.

\section{Literature Review}

Although libraries began to collect sound recordings in the first few decades of the twentieth century, the first rules for indexing and retrieval of such items were developed mid-century by the Music Library Association (MLA). They include the Code for Cataloging Phonograph Records (1942) and the Code for Cataloging Music and Phonorecords (1958). ${ }^{13}$ In the late 1960 s, the Alpha-Numeric System for Classification of Sound Recordings (ANSCR) proposed standards for a hierarchical system to aid with consistency in the organization of sound recordings among different libraries, with genre as the primary level. ${ }^{14}$ In the 1970s, the MLA developed further

11. Òscar Celma and Paul Lamere, "If You Like Radiohead, You Might Like this Article," Al Magazine 32, no. 3 (2011): 57-66.

12. Aaron van den Oord, Sander Dieleman, and Benjamin Schrauwen, "Deep Content-Based Music Recommendation," in Proceedings of the Twenty-seventh Annual Conference on Advances in Neural Information Processing Systems, Lake Tahoe, Nevada, 5-10 December 2013, ed. Christopher J.C. Burges, Léon Bottou, Max Welling, Zoubin Ghahramani and Kilian Q. Weinberger, 1-9.

13. Eric T. Bryant, Music Librarianship: A Practical Guide (Metuchen, NJ: Scarecrow Press, 1985).

14. Carol Saheb-Ettaba and Roger McFarland, Roger, ANSCR: The Alpha-Numeric System for Classification of Recordings (Williamsport, PA: Bro-Dart, 1969). 
standards for machine-readable cataloguing (MARC) records of sound recordings. ${ }^{15}$ As in the case of ANSCR, MARC subject headings focus primarily on genre. ${ }^{16}$ Such tendencies likely relate to the relatively "non-verbal" nature of music, ${ }^{17}$ its apparent lack of "aboutness" when compared to textual works, the range of formats in which music can appear, and the relative rarity of formal musical training among cataloguers. ${ }^{18}$

The aforementioned indexing and retrieval conventions for music did not emerge in isolation. Rather, their formation relates to listeners' explicit or implicit understandings of certain musical or extramusical traits within various genres, which further tie in with listeners' cultural practices and social spaces. ${ }^{19}$ Speaking about popular music in a broad sense, Middleton ${ }^{20}$ discusses how numerous musical and extramusical codes in a piece of music, or at least the degree to which they are present or absent, as well as how they are used, can communicate to listeners (1) a musician's adherence to the conventions of a specific genre and (2) the genre to which a work belongs. In turn, as pointed out by Hamm, ${ }^{21}$ listeners perceive the piece, or the amalgamation of various codes, on the basis of contextualized judgments and perceptions about genre conventions.

Also within the context of popular music, however, complex genre lineages can yield ambiguities that complicate definitive categorizations. ${ }^{22}$ People with different musical backgrounds, expertise, and motivations bring their own assessments to such categorization. Aucouturier and Pachet, ${ }^{23} \mathrm{Holt}_{,}{ }^{24}$ and Negus ${ }^{25}$ note that various interests in the music industry construct genre in ways that suit their own ends and confound pre-existing musical categories. Consequently, the number of possible genres within various taxonomies can range from a

15. Jeff Rehbach, "Computer Technology in the Music Library," in Modern Music Librarianship: Essays in Honor of Ruth Watanabe, ed. Alfred Mann (Stuyvesant, NY: Pendragon Press, 1989), 123-132.

16. Mark McKnight, Music Classification Systems (Lanham, MD: Scarecrow Press, 2002).

17. Elaine Svenonius, “Access to Nonbook Materials: The Limits of Subject Indexing for Visual and Aural Languages," Journal of the American Society for Information Science 45, no. 8 (1994), 600-607.

18. McKnight, Music Classification Systems.

19. Fabian Holt, Genre in Popular Music (Chicago: University of Chicago Press, 2007).

20. Richard Middleton, Studying Popular Music (Philadelphia: Open University Press, 1990).

21. Charles Hamm, "Genre, Performance, and Ideology in the Early Songs of Irving Berlin," In Putting Popular Music in Its Place, ed. Charles Hamm (New York: Cambridge University Press, 1995), 370-80.

22. Ibid.

23. Jean-Julien Aucouturier and Francois Pachet, "Representing Musical Genre: A State of the Art," Journal of New Music Research 32, no. 1 (2003): 83-93.

24. Holt, Genre in Popular Music.

25. Keith Negus, Music Genres and Corporate Cultures (New York: Routledge, 1999). 
handful to several hundred. ${ }^{26}$ Furthermore, a song might appear under different genres in different taxonomies, and a genre in one taxonomy might act as a subgenre within another. ${ }^{27}$ In addition, as mentioned by Cunningham ${ }^{28}$ and Laplante, ${ }^{29}$ individual listeners have their own perceptions of appropriate genre placement. Especially with regard to popular genres, some listeners may find it inappropriate to put stylistically different kinds of music in the same broad category. Conversely, other listeners might not have sufficiently specialized knowledge of music industry norms to understand why seemingly similar-sounding pieces are classified in different genres. ${ }^{30}$ For these reasons, listeners might prefer to employ more individually-pertinent categorization, $^{31}$ rather than top-down genre taxonomies. To some degree, the aforementioned differences in listener perception may relate to the fact that musicians can introduce stylistic codes that transgress the rules of certain genres, leading to the development of "mutations" that provide the foundation for new genres. ${ }^{32}$ Since such works might still convey close associations with antecedents or near-relatives, listeners and scholars of popular music may disagree about the genre to which a piece actually belongs. ${ }^{33}$

In contrast to popular music, categorizations of classical music, or "Western art music," tend to remain relatively stable, primarily due to the prestige that tradition has attached to this music. ${ }^{34}$ Furthermore, at least until the emergence of critical musicology in the late 1980s and early 1990s (and even further back if one counts Adorno's writings on music ${ }^{35}$ ), traditional musicology has tended to emphasize the seeming autonomy of Western art music from its sociocultural contexts. This is in contrast to analyses of popular music, which Borthwick and

26. Stefaan Lippens, Jean-Pierre Martens, Tom De Mulder, and George Tzanetakis, "A Comparison of Human and Automatic Musical Genre Classification," in Proceedings of the IEEE International Conference on Acoustics, Speech, and Signal Processing, Montréal, Québec, 17-21 May 2004 (Piscataway, NJ: IEEE, 2004), 233-36.

27. Aucouturier and Pachet, "Representing Musical Genre."

28. Sally Jo Cunningham, Nina Reeves, and Matthew Britland, "An Ethnographic Study of Music: Implications for the Design of a Music Digital Library," in Proceedings of the Third ACM/IEEE-CS Joint Conference on Digital Libraries, London, United Kingdom (Washington, DC: IEEE Computer Society, 2003), 5-15.

29. Laplante, Audrey, "Everyday Life Music Information-Seeking Behaviour of Young Adults: An Exploratory Study" (PhD diss., McGill University, 2008).

30. Ibid.

31. Ibid.

32. Fabbri, Franco, "What Kind of Music?" trans. Ivan Chambers, Popular Music 2 (1982): 131-43.

33. Cope, Black Sabbath and the Rise of Heavy Metal Music.

34. Fabbri, "What Kind of Music?"

35. Theodor W. Adorno, Essays on Music, selected with introduction, commentary, and notes by Richard Leppert; new translations by Susan H. Gillespie (Berkeley: University of California Press, 2002). 
Moy, ${ }^{36}$ Cope, ${ }^{37}$ and Green ${ }^{38}$ describe as tending to focus on its sociocultural aspects, rather than the traits of the music itself.

Even with the persistence of the oversimplified dichotomy underlying the "classical vs. popular" divide, authors such as Long, ${ }^{39}$ Ross, ${ }^{40}$ Schleifer, ${ }^{41}$ and Sullivan ${ }^{42}$ describe how numerous examples of genre transgressions and mutations ${ }^{43}$ have occurred between them. Furthermore, in relation to Laplante's dissertation ${ }^{44}$ on music information-seeking practices, Laplante and Downie describe how young adult listeners' ideas about "legitimate" music in 2000s Montreal varied from those found by sociologist Pierre Bourdieu in 1960s France: "One thing that differed from Bourdieu's results was that legitimate tastes were not associated with classical or jazz music, but with independent, underground music, which, some participants were proud to say, is not as 'easy' or 'accessible' as popular music." ${ }^{45}$ In other words, one could ascribe traits of "universality, complexity, and originality," music, to certain kinds of popular music.

However one explains it, the history of genre transgressions and mutations hints at the possibility of connections among various kinds of music, and alternative conceptualizations of musical similarity become potentially useful to people looking for music from unfamiliar genres. As described in the music information retrieval literature, ${ }^{47}$ as well as writings in music psychology by Gabrielsson ${ }^{48}$ and Wedin, ${ }^{49}$ musical and extramusical traits associated with

36. Stuart Borthwick and Ron Moy, Popular Music Genres: An Introduction (New York: Routledge, 2004).

37. Cope, Black Sabbath and the Rise of Heavy Metal Music.

38. Lucy Green, "Ideology," in Key Terms in Popular Music and Culture, ed. Bruce Horner and Thomas Swiss (Malden, MA: Blackwell, 1999), 5-17.

39. Long, Beautiful Monsters.

40. Ross, The Rest Is Noise.

41. Schleifer, Modernism and Popular Music.

42. Sullivan, New World Symphonies.

43. Fabbri, "What Kind of Music?"

44. Laplante, "Everyday Life Music Information-Seeking Behaviour of Young Adults."

45. Audrey Laplante and J. Stephen Downie, "The Utilitarian and Hedonic Outcomes of Music InformationSeeking in Everyday Life," Library \& Information Science Research 33, no. 3 (2011): 208.

46. Green, "Ideology," 7.

47. J. Stephen Downie, "Music Information Retrieval," in Annual Review of Information Science and Technology, ed. Blaise Cronin (Medford, NJ: Information Today, 2003), 295-340.

48. Alfred Gabrielsson, "The Relationship between Musical Structure and Perceived Expression," in Oxford Handbook of Music Psychology, ed. Susan Hallam, Ian Cross, and Michael Thaut (New York: Oxford University Press, 2009), 141-150.

49. Lage Wedin, "A Multidimensional Study of Perceptual-Emotional Qualities in Music," Scandinavian Journal of Psychology 13, no. 1 (1972), 241-257. 
listeners' favourite music could act as entrées that enable such discovery. For this reason, my doctoral research focuses on the opinions of self-described and self-selected "avid recreational music listeners," ${ }^{50}$ who consider music an integral part of their lives.

\section{Research Methodology}

Although my doctoral study asks a variety of questions about music information-seeking behaviours, it focuses primarily on the ways avid recreational music listeners perceive musical similarity and the importance of genre as an indicator. Potential clues about alternative notions of similarity emerge in the work done by Lamere ${ }^{51}$ and Bischoff et al. ${ }^{52}$ on tagging practices associated with music, wherein more colloquial alternatives to genre may emerge as additional signifiers of similarity. Similar principles apply to studies by Baumann and Halloran, ${ }^{53}$ as well as Roos and Manaris, ${ }^{54}$ who designed experimental systems that draw upon audio signals, rather than textual information about music. Nonetheless, the comparatively small number of studies about music information-seeking practices, by Cunningham et al., ${ }^{55}$ Inskip et al.,, ${ }^{56}$ Laplante, ${ }^{57}$ and Laplante and Downie, ${ }^{58}$ typically discuss similarity as one topic among many, rather than a specific focus. Taking the aforementioned factors into account, this study employs the following research questions:

50. Laplante's 2008 dissertation refers to several, but not all, participants as "avid music listeners." This study builds on the usage of that phraseology by adding the word "recreational," with the intention of focusing on persons who listen to music for leisure, pleasure, enjoyment, and the like. Along with determining how "avid recreational music listeners" conceptualize musical similarity, it is hoped that the data gathered from self-selected participants will also aid in developing a formalized definition of such persons.

51. Paul Lamere, "Social Tagging and Music Information Retrieval," Journal of New Music Research 37, no. 2 (2008): 101-114.

52. Kerstin Bischoff, Claudiu S. Firan, Wolfgang Nejdi, and Raluca Paiu, "Bridging the Gap between Tagging and Querying Vocabularies: Analyses and Applications for Enhancing Multimedia IR," Web Semantics: Science, Services and Agents on the World Wide Web 8, nos. 2-3 (2010): 97-109.

53. Stephan Baumann and John Halloran, "An Ecological Approach to Multimodal Subjective Music Similarity Perception," in Proceedings of the Conference on Interdisciplinary Musicology (CIM04) Graz, Austria, 15-18 April, 2004, ed. Richard Parncutt, Annkatrin Kessler, and Frank Zimmer, 1-6.

54. Patrick Roos and Bill Manaris, "A Music Information Retrieval Approach Based on Power Laws," in Proceedings of the Nineteenth IEEE International Conference on Tools with Artificial Intelligence, Patras, Greece (Piscataway, NJ: IEEE, 2007), 27-31.

55. Cunningham, Reeves, and Britland, "An Ethnographic Study of Music."

56. Charles Inskip, Richard Butterworth, and Andrew MacFarlane, "A Study of the Information Needs of the Users of a Folk Music Library and the Implications for the Design of a Digital Library System," Information Processing \& Management 44, no. 2 (2008): 647-662.

57. Laplante, "Everyday Life Music Information-Seeking Behaviour of Young Adults."

58. Laplante and Downie, "The Utilitarian and Hedonic Outcomes of Music Information-Seeking in Everyday Life." 
- RQ1: How do listeners search for music, or information about music?

- RQ2: What motivates listeners to search for music, or information about music? How do they use such information?

- RQ3: How do listeners conceptualize similarity? To what extent do listeners conceptualize similarity on the basis of genre?

- RQ4: To what extent do searching and browsing tools and techniques impact perceptions of similarity?

- RQ5: To what extent does serendipitously finding music with similar traits, but from different genres, influence listeners' experiences of music information seeking? To what extent is such discovery important to them?

The findings will describe listeners' assessments of the usefulness of genre for categorizing music, and of the ways that current recommender systems typically operate. Furthermore, the study will provide insights into the ways in which listeners conceptualize "similarity," regardless of the structures of pre-existing systems for categorization and recommendation.

The self-selected "avid recreational music listeners" in this study are required to be at least 18 years of age, and they must not work with music in a professional capacity. The latter exclusion is intended to aid with understanding how non-professionals conceptualize their experiences with music, and to gauge their use of related technical terminology. However, the study includes respondents who regularly listen to music while engaging in other activities, as well as those who perform in amateur capacities. Following suggestions made by Lincoln and Guba ${ }^{59}$ with regard to saturation points in qualitative research, along with the numbers of participants used in similar research, this study is gathering data from 20 respondents. ${ }^{60}$

Recruitment for the study centres around London, Ontario, which has a population of more than $365,000,{ }^{61}$ two institutions of higher learning (Fanshawe College and Western University), and a central location between two larger metropolitan areas (Detroit, Michigan; and the Greater Toronto Area). Furthermore, it has a reputation as an "average" test market for

59. Yvonna S. Lincoln and Egon G. Guba, Naturalistic Inquiry (Beverly Hills, CA: Sage, 1985).

60. At the time of submission, interviews have been conducted with 18 participants.

61. Statistics Canada, Focus on Geography Series, 2011 Census, http://www12.statcan.gc.ca/censusrecensement/2011/as-sa/fogs-spg/Facts-cma-eng.cfm?LANG=Eng\&GK=CMA\&GC=555. 
introducing new products, services, and companies in Canada, ${ }^{62}$ such as Tim Hortons dark roast coffee. ${ }^{63}$ Recruitment notices with tear-off tabs have been posted in a variety of venues, including public libraries, community centres, London's two major institutions of higher learning, and specialized music stores, to reflect a diverse demographic range. Word of mouth and snowballing have also acted as recruitment tools.

Following the increasingly popular "user-centred" approach that has emerged within library and information science (LIS) research over the past two decades, ${ }^{64}$ as exemplified in studies by Harris and Dewdney, ${ }^{65}$ Savolainen, ${ }^{66}$ and Laplante, ${ }^{67}$ in-depth semi-structured interviews act as the primary research technique. Such interviews have been used in studies on music information seeking, as well as studies in readers' advisory (RA). Even though RA is a separate area within LIS, it shares some elements relevant to music information behaviour research. These include an interest in the ways recreational readers find new books they might enjoy, and the degree to which various modes of categorization relate to their searches. RA studies also compensate for the relatively small amount of research about listeners and music information. As seen in studies by Dali, ${ }^{68}$ Kofmel, $^{69}$ Moyer, ${ }^{70}$ Ooi and Liew, ${ }^{71}$ Ross, $^{72}$ and

62. Kelly Pedro, "Picture Perfect(ly) Average," London Free Press, November 7, 2011, http://www.Ifpress.com/news/london/2011/11/03/18922301.html.

63. Hollie Shaw, "Tim Hortons to Offer New Dark Roast Coffee Blend in Two Test Markets," Financial Post, October 28, 2013, http://business.financialpost.com/2013/10/28/tim-hortons-dark-roast-coffee/.

64. Brenda Dervin, "What Methodology Does to Theory: Sense-Making Methodology as Exemplar," in Theories of Information Behavior, ed. Karen E. Fisher, Sandra Erdelez, \& Lynne (E.F.) McKechnie (Medford, NJ: Information Today, 2005), 25-30.

65. Roma Harris and Patricia Dewdney, Barriers to Information: How Formal Help Systems Fail Battered Women (Westport, CT: Greenwood, 1994).

66. Reijo Savolainen, "Everyday Life Information Seeking: Approaching Information Seeking in the Context of 'Way of Life'," Library \& Information Science Journal 17, no. 3 (1995): 259-94.

67. Laplante, "Everyday Life Music Information-Seeking Behaviour of Young Adults."

68. Keren Dali, “'Ask Me What I Read': Readers' Advisory and Immigrant Adaptation,” New Library World 114, nos. 11-12 (2013): 507-26.

69. Kim G. Kofmel, "Adult Readers of Science Fiction and Fantasy: A Qualitative Study of Reading Preference and Genre Perception" (PhD diss., University of Western Ontario, 2002).

70. Jessica E. Moyer, "Learning from Leisure Reading: A Study of Adult Public Library Patrons," Reference \& User Services Quarterly 46, no. 4 (2007): 66-78.

71. Kamy Ooi and Chern Li Liew, "Selecting Fiction as Part of Everyday Life," Journal of Documentation 67, no. 5 (2011): 748-72.

72. Catherine S. Ross, "Finding without Seeking: The Information Encounter in the Context of Reading for Pleasure," Information Processing and Management 35, no. 6 (1999): 783-99. 
Rothbauer, ${ }^{73}$ the scope and methodological approaches of RA provide additional foundations for the present study's design. The interviews take place in public venues agreed upon by both the participants and the researcher, ideally on the basis of atmosphere and safety. In order to gain rich data on respondents' music information-seeking behaviours, the interview guidelines consist of foundational questions, with deviations occurring when deemed appropriate by the researcher and participant. Ideally, the interviews take approximately one hour, although several have lasted close to two hours, and a few have taken approximately three hours.

Data from the interviews will be triangulated with participant observation, using the "thinkaloud" protocol, which allows researchers to observe the activities in which people engage "live." Whether done within online platforms, music stacks in libraries, or other places where listeners might search or browse for music, this approach can complement the interviews' selfreports on past experiences. ${ }^{74}$ For this task, participants are asked to look for music they consider similar, regardless of whether it is based on genre, or some other musical or extramusical trait. It also provides an opportunity to find new music "live," based on what they already enjoy. Interestingly, however, some participants have declined to do the exercise, citing such reasons as (1) not wanting to be watched, (2) lack of time, or (3) the exercise not reflecting the ways they typically find music. ${ }^{75}$ In lieu of doing the exercise, some prefer to discuss hypothetical scenarios or expand on the interview discussion. For those who have done the exercise, it typically takes around 15 minutes.

At the end of each session, participants fill out a questionnaire of demographic data, based on "short form" census information collected by Statistics Canada in $2006^{76}$ and 2011, ${ }^{77}$ as well as questions from other studies about music information seeking and RA. The questionnaire aids in determining whether the sample reasonably represents the London and Middlesex County

73. Paulette M. Rothbauer, "Finding and Creating Possibility: Reading in the Lives of Lesbian, Bisexual and Queer Young Women" (PhD diss., University of Western Ontario, 2004).

74. Norman Blaikie, Designing Social Research: The Logic of Anticipation (Malden, MA: Polity, 2010).

75. The exercise was intended to replicate how participants typically look for (and discover) new music, which is one of the main reasons why it remains relatively unstructured. The original conceptualization also assumed that such seeking would occur within a systems-based context. However, some participants stated that they do not typically search or browse for music in such a manner. Rather, some usually find music in relatively "passive" ways, whether through recommendations by people they know, or serendipitous encounters in a variety of media and venues (such as concerts). Even in an open-ended exercise, such conditions cannot be replicated easily, if at all.

76. Statistics Canada, Census 2006 - 2A (Short Form), http://www12.statcan.gc.ca/census-recensement/2006/ ref/about-apropos/version2A-eng.cfm.

77. Statistics Canada, 2011 Census (2A), http://www23.statcan.gc.ca/imdb-bmdi/pub/instrument/3901 Q1 v4-eng.pdf. 
region. Gaps that emerge can provide the basis for future research about specific groups of people, including those that have been historically underrepresented.

Originally proposed by Glaser and Strauss, ${ }^{78}$ a grounded theory approach will be used to analyze the data, which consists of transcriptions from recorded interviews and field notes. The latter are important for highlighting salient points made by participants, especially if they either do not wish to be recorded, or if the recording somehow disappears before transcription is completed. The open-ended nature of grounded theory, which examines patterns, categories, and relationships that emerge from engagement with the data on its own terms, is appropriate due to the relatively small number of contextualized studies about music information seeking, as well as the lack of studies about musical similarity.

As pointed out by Blaikie, ${ }^{79}$ Charmaz, $^{80}$ and Patton, ${ }^{81}$ an essential aspect of grounded theory is coding, which aids researchers with identifying concepts that emerge from their research, developing categories and subcategories for such concepts, and formulating theoretical frameworks. Throughout this process, memo-writing further strengthens the rationale behind the identification of patterns from the study. Building upon the data (in this study, interview transcriptions and field notes), memo-writing provides a foundation upon which broader abstractions eventually emerge, giving rise to conceptualizations and categories. This is followed by theoretical coding, which attempts to identify yet broader patterns and connections. Due to grounded theory's inductive nature, patterns that become apparent in newer data might require re-examination of earlier respondents' transcripts. $^{82}$

\section{Conclusion}

Taking into consideration the ambiguities of such seemingly "fixed" categories as genre, an open-ended approach to both genre and similarity in relation to music is appropriate. Whatever the findings, this study has direct implications for areas of LIS concerned with music, including categorization practices and recreational listeners' information behaviours. Certainly at a practical level, awareness of the broad possibilities of musical similarity, and perhaps by extension "omnivorousness" ${ }^{83}$ of musical tastes, can inform the development of more nuanced

78. Barney G. Glaser and Anselm L. Strauss, The Discovery of Grounded Theory: Strategies for Qualitative Research (Chicago: Aldine, 1967).

79. Blaikie, Designing Social Research.

80. Kathy Charmaz, Constructing Grounded Theory: A Practical Guide through Qualitative Analysis (Thousand Oaks, CA: SAGE, 2006).

81. Michael Q. Patton, Qualitative Research and Evaluation Methods (Thousand Oaks, CA: Sage, 2002).

82. Charmaz, Constructing Grounded Theory.

83. Peterson and Kern, "Changing Highbrow Taste." 
ways for listeners to find music they perceive as similar to what they already enjoy, whether within the same genre or across genres. Of course, this study does not intend to answer all questions about perceptions of musical similarity. Rather, both the study and its foundational literature act as starting points for discussion about the topic at a variety of levels and within a variety of contexts.

\section{Bibliography}

Adorno, Theodor W. Essays on Music. Selected with introduction, commentary, and notes by Richard Leppert. New translations by Susan H. Gillespie. Berkeley: University of California Press, 2002.

Aucouturier, Jean-Julien, and Francois Pachet. "Representing Musical Genre: A State of the Art." Journal of New Music Research 32, no. 1 (2003): 83-93.

Baumann, Stephan, and John Halloran. "An Ecological Approach to Multimodal Subjective Music Similarity Perception." In Proceedings of the Conference on Interdisciplinary Musicology (CIM04) Graz, Austria, 15-18 April, 2004, edited by Richard Parncutt, Annkatrin Kessler, and Frank Zimmer, 1-6.

Bischoff, Kerstin, Claudiu S. Firan, Wolfgang Nejdi, and Raluca Paiu. "Bridging the Gap between Tagging and Querying Vocabularies: Analyses and Applications for Enhancing Multimedia IR." Web Semantics: Science, Services and Agents on the World Wide Web 8, nos. 2-3 (2010): 97-109.

Blaikie, Norman. Designing Social Research: The Logic of Anticipation. Malden, MA: Polity, 2010. Bonhard, Philip, and Martina Angela Sasse. "Knowing Me, Knowing You: Using Profiles and Social Networking to Improve Recommender Systems." BT Technology Journal 24, no. 3 (2006): 84-98.

Borthwick, Stuart, and Ron Moy. Popular Music Genres: An Introduction. New York: Routledge, 2004.

Bryant, Eric T. Music Librarianship: A Practical Guide. Metuchen, NJ: Scarecrow Press, 1985.

Celma, Òscar. Music Recommendation and Discovery. Berlin, Heidelberg: Springer-Verlag Berlin Heidelberg, 2010.

Celma, Òscar, and Paul Lamere. "If You Like Radiohead, You Might Like this Article." Al Magazine 32, no. 3 (2011): 57-66.

Charmaz, Kathy. Constructing Grounded Theory: A Practical Guide through Qualitative Analysis. Thousand Oaks, CA: Sage, 2006.

Cope, Andrew. Black Sabbath and the Rise of Heavy Metal Music. Burlington, VT: Ashgate, 2010. Cunningham, Sally Jo, Nina Reeves, and Matthew Britland. "An Ethnographic Study of Music: Implications for the Design of a Music Digital Library." In Proceedings of the Third 
ACM/IEEE-CS Joint Conference on Digital Libraries, London, United Kingdom, 5-15.

Washington, DC: IEEE Computer Society, 2003.

Dali, Keren. "'Ask Me What I Read': Readers' Advisory and Immigrant Adaptation." New Library World 114, nos. 11-12 (2013): 507-26.

Dervin, Brenda. "What Methodology Does to Theory: Sense-Making Methodology as Exemplar." In Theories of Information Behavior, edited by Karen E. Fisher, Sandra Erdelez, \& Lynne (E.F.) McKechnie, 25-30. Medford, NJ: Information Today, 2005.

Downie, J. Stephen. "Music Information Retrieval." In Annual Review of Information Science and Technology, edited by Blaise Cronin, 295-340. Medford, NJ: Information Today, 2003.

Fabbri, Franco. "What Kind of Music?" Translated by Ivan Chambers. Popular Music 2 (1982): 131-143.

Gabrielsson, Alfred. "The Relationship between Musical Structure and Perceived Expression." In Oxford Handbook of Music Psychology, edited by Susan Hallam, lan Cross, and Michael Thaut, 141-150. New York: Oxford University Press, 2009.

Glaser, Barney G., and Anselm L. Strauss. The Discovery of Grounded Theory: Strategies for Qualitative Research. Chicago: Aldine, 1967.

Green, Lucy. "Ideology." In Key Terms in Popular Music and Culture, edited by Bruce Horner and Thomas Swiss, 5-17. Malden, MA: Blackwell, 1999.

Hamm, Charles. "Genre, Performance, and Ideology in the Early Songs of Irving Berlin." In Putting Popular Music in Its Place, edited by Charles Hamm, 370-80. New York: Cambridge University Press, 1995.

Harris, Roma, and Patricia Dewdney. Barriers to Information: How Formal Help Systems Fail Battered Women. Westport, CT: Greenwood, 1994.

Holt, Fabian. Genre in Popular Music. Chicago: University of Chicago Press, 2007.

Inskip, Charles, Richard Butterworth, and Andrew MacFarlane. "A Study of the Information Needs of the Users of a Folk Music Library and the Implications for the Design of a Digital Library System." Information Processing \& Management 44, no. 2 (2008): 647662.

Kofmel, Kim G. "Adult Readers of Science Fiction and Fantasy: A Qualitative Study of Reading Preference and Genre Perception." PhD diss., University of Western Ontario, 2002.

Lamere, Paul. "Social Tagging and Music Information Retrieval." Journal of New Music Research 37, no. 2 (2008): 101-114.

Laplante, Audrey. "Everyday Life Music Information-Seeking Behaviour of Young Adults: An Exploratory Study." PhD diss., McGill University, 2008.

Laplante, Audrey, and J. Stephen Downie. "The Utilitarian and Hedonic Outcomes of Music Information-Seeking in Everyday Life." Library \& Information Science Research 33, no. 3 (2011): 202-10.

Lincoln, Yvonna S., and Egon G. Guba. Naturalistic Inquiry. Beverly Hills, CA: Sage, 1985. 
Lippens, Stefaan, Jean-Pierre Martens, Tom De Mulder, and George Tzanetakis. "A Comparison of Human and Automatic Musical Genre Classification." In Proceedings of the IEEE International Conference on Acoustics, Speech, and Signal Processing, Montréal, Québec, 17-21 May 2004, 233-36. Piscataway, NJ: IEEE, 2004.

Long, Michael. Beautiful Monsters: Imagining the Classic in Musical Media. Berkeley, CA: University of California Press, 2008.

McKnight, Mark. Music Classification Systems. Lanham, MD: Scarecrow Press, 2002.

Middleton, Richard. Studying Popular Music. Philadelphia: Open University Press, 1990.

Moyer, Jessica E. "Learning from Leisure Reading: A Study of Adult Public Library Patrons." Reference \& User Services Quarterly 46, no. 4 (2007): 66-78.

Negus, Keith. Music Genres and Corporate Cultures. New York: Routledge, 1999.

Ooi, Kamy, and Chern Li Liew. "Selecting Fiction as Part of Everyday Life." Journal of Documentation 67, no. 5 (2011): 748-72.

Patton, Michael Q. Qualitative Research and Evaluation Methods. Thousand Oaks, CA: Sage, 2002.

Pedro, Kelly. (2011). “Picture Perfect(ly) Average.” London Free Press, November 7, 2011. http://www.Ifpress.com/news/london/2011/11/03/18922301.html.

Peterson, Richard A., and Roger M. Kern. "Changing Highbrow Taste: From Snob to Omnivore." American Sociological Review 61, no. 5 (1996): 900-907.

Peterson, Richard A., and Albert Simkus. "How Musical Taste Groups Mark Occupational Status Groups." In Cultivating Differences: Symbolic Boundaries and the Making of Inequality, edited by Michèle Lamont and Marcel Fournier, 152-68. Chicago: University of Chicago Press, 1992.

Rehbach, Jeff. "Computer Technology in the Music Library." Modern Music Librarianship: Essays in Honor of Ruth Watanabe, edited by Alfred Mann, 123-32. Stuyvesant, NY: Pendragon Press, 1989.

Roos, Patrick, and Bill Manaris. A Music Information Retrieval Approach Based on Power Laws. Proceedings of the Nineteenth IEEE International Conference on Tools with Artificial Intelligence, Patras, Greece, 27-31. Piscataway, NJ: IEEE, 2007.

Ross, Alex. The Rest Is Noise: Listening to the Twentieth Century. New York: Farrar, Straus and Giroux, 2007.

Ross, Catherine S. "Finding without Seeking: The Information Encounter in the Context of Reading for Pleasure." Information Processing and Management, 35, no. 6 (1999): 78399.

Rothbauer, Paulette M. "Finding and Creating Possibility: Reading in the Lives of Lesbian, Bisexual and Queer Young Women." PhD diss., University of Western Ontario, 2004.

Saheb-Ettaba, Carol, and McFarland, Roger. ANSCR: The Alpha-Numeric System for Classification of Recordings. Williamsport, PA: Bro-Dart, 1969. 
Savolainen, Reijo. "Everyday Life Information Seeking: Approaching Information Seeking in the Context of 'Way of Life.'” Library \& Information Science Journal 17, no. 3 (1995): 259-94. Schleifer, Ronald. Modernism and Popular Music. New York: Cambridge University Press, 2011. Shaw, Hollie. "Tim Hortons to Offer New Dark Roast Coffee Blend in Two Test Markets." Financial Post, October 28, 2013. http://business.financialpost.com/2013/10/28/tim-hortons-dark-roast-coffee/.

Statistics Canada. Census 2006 - 2A (Short Form), 2006. http://www12.statcan.gc.ca/censusrecensement/2006/ref/about-apropos/version2A-eng.cfm.

- - . . Focus on Geography Series, 2011 Census. Statistics Canada Catalogue no. 98-310XWE2011004. Ottawa, ON: Analytical products, 2012. http://www12.statcan.gc.ca/census-recensement/2011/as-sa/fogs-spg/Facts-cmaeng.cfm?LANG=Eng\&GK=CMA\&GC=555.

- - . 2011 Census (2A), 2011. http://www23.statcan.gc.ca/imdb-bmdi/pub/instrument/ 3901 Q1 V4-eng.pdf.

Sullivan, Jack. New World Symphonies: How American Culture Changed European Music. New Haven: Yale University Press, 1999.

Svenonius, Elaine. "Access to Nonbook Materials: The Limits of Subject Indexing for Visual and Aural Languages." Journal of the American Society for Information Science 45, no. 8 (1994), 600-607.

van den Oord, Aaron, Sander Dieleman, and Benjamin Schrauwen. "Deep Content-Based Music Recommendation." In Proceedings of the Twenty-seventh Annual Conference on Advances in Neural Information Processing Systems, Lake Tahoe, Nevada, 5-10 December 2013, edited by Christopher J.C. Burges, Léon Bottou, Max Welling, Zoubin Ghahramani and Kilian Q. Weinberger, 1-9.

Wedin, Lage. "A Multidimensional Study of Perceptual-Emotional Qualities in Music." Scandinavian Journal of Psychology 13 (1972), 241-257. 